\title{
Talking-Head, Realism Level and Emotions in Learning: A Conceptual Framework
}

\author{
Muhammad Ihsan Rokeman, Ahmad Zamzuri Mohamad Ali, and Mohd Khairulnizam Ramlie
}

\begin{abstract}
The talking-head animation has potential in attracting students' attention and as such, it can be used as an effective instructional tool in various learning conditions. However, its use could cause emotional disturbances and feelings of uneasiness among learners. Especially, if the design of the talking-head character is too realistic that resembles an actual human. Such condition is also known as the Uncanny Valley phenomenon. In this paper, a research conceptual framework on the role of talking-head animation with varying levels of realism and its effects on students' emotions in learning will be addressed. In particular, the discussion will be grounded on the relevant theories and principles and also based on review of the relevant literature.
\end{abstract}

Index Terms-Emotion, pedagogical agent, realistic level, talking-head, uncanny valley.

\section{INTRODUCTION}

Rapid advancement in computer and multimedia technology, especially in the area of digital animation has made the design, development and implementation of this multimedia component become faster and easier. Profoundly, impacting many diverse areas and fields including education [1]. In fact, this advancement has heightened the needs of innovating it for effective use in the teaching and learning process in the classroom [1], [2]. To date, a host of strategies in presenting digital animation that serves as learning aids are available, one of which is the talking-head animation.

Basically, the talking-head animation is a digital character designed to look like the human face that can speak or verbalize words by synchronizing the movements of its lips with the audio narration. In particular, talking-head animated displays are only limited from head to shoulders. The audio narration of the talking-head can be the recorded audio from the actual teaching of a teacher in the classroom. Therefore, the animator or developer only need to focus on animating the talking-head accordingly with the relevant animation software. Nowadays, numerous software are available for the purpose, among is Crazy Talk.

This condition gives a strong, vivid impression of a character that speaks or explains like an actual human being [3]. In this regard, the proper design and use of the

Manuscript received March 18, 2020; revised May 22, 2020. This work was supported by Ministry of Education and Universiti Pendidikan Sultan Idris (UPSI) under FRGS grant (FRGS/1/2018/SS109/UPSI/01/1).

Muhammad Ihsan Rokeman and Ahmad Zamzuri Mohamad Ali are with Faculty of Art, Computing and Creative Industry, Universiti Pendidikan Sultan Idris, 35900 Tanjong Malim, Perak, Malaysia (e-mail: ihsan.psas@gmail.com,zamzuri@fskik.upsi.edu.my).

Mohd Khairulnizam Ramlie is with Faculty of Art and Design, Universiti Teknologi Mara, Perak Branch, Seri Iskandar campus, Malaysia (e-mail: mohdk823@uitm.edu.my). talking-head animation can surely help in enhancing students' motivation and maintaining their motivation throughout the learning process [4], [5].

\section{Talking-Head as a Pedagogical Agent}

Over the recent years, many digital virtual characters have been widely used as pedagogical agents in a diverse range of fields and contexts, such as the characters of video games or as avatars for online applications [6]. In principle, a pedagogical agent is a virtual character displayed on a computer screen that plays the role of delivering or presenting the learning contents in multimedia environments [7], [8]. Typically, such an agent is designed in various forms such as animals [9], objects, and organic characters resembling the human [10] and talking-head as well [11]. Whereby, this article will only focuses on talking-head as pedagogical agent.

In particular, a talking-head pedagogical agent can be presented in a spectrum of extremities, from being a simple character such as animated static image to a complex one such as a 3D animation [12]. Fig. 1 shows various forms of pedagogical or virtual agent characters used in various applications.
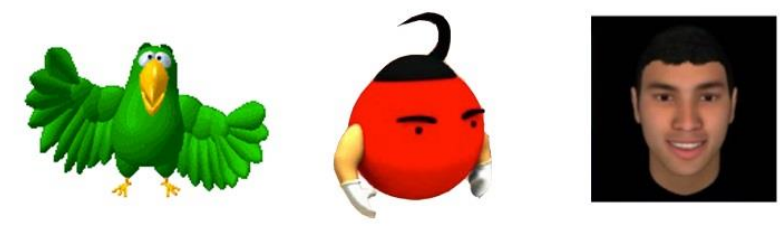

Fig. 1. (Left) - an animal-like character [9], (Center) - an object-based character [10], (Right) - a talking-head [11].

In principle, a talking-head animation displayed on a screen interacts with the user using voice or texts [3], [13]. In this respect, the application as multimedia-based learning material can certainly assist in creating a conducive and effective learning environment [14]. The talking-head animation has the ability in attracting students' attention to ensure that they stay in learning for longer time and duration. This will also ensure that students will persistently be engaged in the learning activities, which could make the learning both educational and fun [13]. Ultimately, affecting a positive impact on their emotions and motivation as well [11], [15]. In addition, from the psychological perspective, the use of such a novel learning aid can assist students in dealing with their negative emotions, such as anxiety, in learning certain subjects or courses [7].

Despite the recognition of the educational benefits of using 
the talking-head animation, several scholars have been cautionary in advocating a wholesale use of such aid, given that some studies have shown less promising findings. For example, a study carried out by [16], who examined the effects of using a talking-head animation with various levels of realism, found that there was no significant impact on the learning performance. Meanwhile, a study by [17] found that there were no significant effects on emotion between an experimental group that used learning materials enhanced with a talking-head animation and the control group that used text displayed on the computer screen.

In view of the inconsistency in the findings of previous studies, it can be reasonably argued that it is vital to prioritize the selection of a proper character of the talking-head in designing and developing instructional materials. Failing to heed this priority can have a serious repercussion that can adversely affect students' learning [17]. In view of such heed, [18] strongly advocate that the design of the character of the talking-head must closely resemble the human face as naturally as possible, but it must not be too realistic. Otherwise, a digital character looking too real like a human would make users less receptive, inducing a sense of lack of confidence with such a character [19].

\section{TALKING-HEAD AND EMOTIONS}

Arguably, the proper use of a character of a talking-head together with other learning materials can help induce and sustain positive emotions of students throughout the learning process [20], [21]. Nevertheless, studies on talking-head animation with varying levels of realism have shown that such a character would induce a range of emotions, with some becoming negative as the levels of realism reached high realism resembling the human appearance [22]. Apparently, a character that is too realistic can badly affect users' emotions, making them feel uncomfortably uneasy [23], [24]. As widely acknowledged, emotions wield a significant impact on students' motivation, with positive emotions being able to motivate students to persist in learning. However, the reverse is true with negative emotions that demotivate students to continue with their learning [25], [26]. Surely, emotions can have a profound impact on students' learning, the effectiveness of which depends on the type of emotions as being either positive or negative.

In addition, the facial expression of the character of the talking-head may also influence users' emotions. Essentially, such expressions can be divided into several types of emotions, such as anger, fear, happiness, sadness, surprises or neutral expression [22]. In particular, users see positive facial expressions, such as a happy expression, as being friendlier or more cordial that helps create a positive effect on their emotions compared with negative facial expressions [22]. Thus far, previous studies have not specifically focused on examining the expression factor and the level of realism of the character of the talking head, particularly in investigating their impacts on the learning motivation of the students.

Based on a review of previous studies, it can be reasonably argued that the talking-head character that is too realistic can have a negative effect on users' emotions compared with such a character that is not too realistic [27]. Clearly, such an argument begs a question; will a character of the talking-head with varying levels of positive expression produce the same results as above? Arguably, a positive facial expression, such as smiling, will probably be more effective in eliminating or minimizing negative effects on users' emotions.

\section{THEORETICAL FRAMEWORK}

The theoretical framework developed in this study is based on the theory of Control-Value of Achievement Emotions that deals with emotions in learning and on the Uncanny Valley phenomenon. Essentially, the theory of Control-Value of Achievement Emotions, which was conceptualized by Pekrun [28], focuses on the emotions of achievement that aims to analyze the causes of changes in emotions and the effects of such emotions on individuals in the learning environment [28], [29]. More specifically, in the learning context, achievement emotions are emotions personally and directly felt by students based on their attained achievements derived from the learning activities in which they have participated [30]-[33].

Theoretically, such a theory posits that achievement emotions can be divided into three values or dimensions, namely emotional reactions (being either positive or negative), the level of emotional activation (activating or de-activating), and the object focus (the activity or the learning outcome) [30]. From these three dimensions, a three-dimensional taxonomy was developed accordingly to explain the concept of achievement emotions [31], as shown in Fig. 2.

\begin{tabular}{|c|c|c|c|c|}
\hline \multirow[b]{2}{*}{$\begin{array}{l}\text { Object } \\
\text { Focus }\end{array}$} & \multicolumn{2}{|c|}{ Positive } & \multicolumn{2}{|c|}{ Negative } \\
\hline & Activating & Deactivating & Activating & Deactivating \\
\hline $\begin{array}{c}\text { Activity } \\
\text { Focus }\end{array}$ & - Enjoyment & - Relaxation & $\begin{array}{l}\text { - Anger } \\
\text { - Frustration }\end{array}$ & - Boredom \\
\hline $\begin{array}{c}\text { Outcome } \\
\text { Focus }\end{array}$ & $\begin{array}{l}\text { - Joy } \\
\text { - Hope } \\
\text { - Pride } \\
\text { - Gratitude }\end{array}$ & $\begin{array}{l}\text { - Contentment } \\
\text { - Relief }\end{array}$ & $\begin{array}{l}\text { - Anxiety } \\
\text { - Shame } \\
\text { - Anger }\end{array}$ & $\begin{array}{l}\text { - Sadness } \\
\text { - Disappointment } \\
\text { - Hopelessness }\end{array}$ \\
\hline
\end{tabular}

Fig. 2. The three-dimensional taxonomy of achievement emotions based on the theory of Control-Value of Achievement Emotions [31].

Based on the three dimensional taxonomy of achievement emotions, positive emotions experienced by students during learning activities can be divided into two levels of emotional activation, namely activating (e.g., happiness enjoyment) and de-activating (e.g., relaxation). In particular, positive emotions, such as the feelings of fun or happiness (enjoyment), felt during learning can help improve students' motivation; in contrast, negative emotions, such as the feeling of boredom, can adversely affect their motivation in learning [20], [34].

Premised in this context, a study that examine the dimension of positive emotional reaction (e.g., the feeling of fun) and identifying the level of realism of the talking-head character that can enhance students' positive emotions in learning seems relevant. 
The second theory grounded is based on the Uncanny Valley phenomenon, which essentially explicates the relationship between the level of a character's realism and the level of comfortableness and human emotions [24], which is graphically represented by Fig. 3. Specifically, this theory propounds that an animated character that looks too realistic would negatively affect the level of comfortableness and the emotions of users who are watching such a character [23], [24], [35]. As such, it is vital to emphasize the proper selection of the level of realism to be used in the development process of an animated character. The failure of which can be detrimental to students' state of emotion, in which the Uncanny Valley phenomenon can materialize [4], [36], [37]. In view of this risk, the study on the theory of Uncanny Valley to examine whether students' emotions induced by the various talking-head character design approach could affect their learning seems also important.

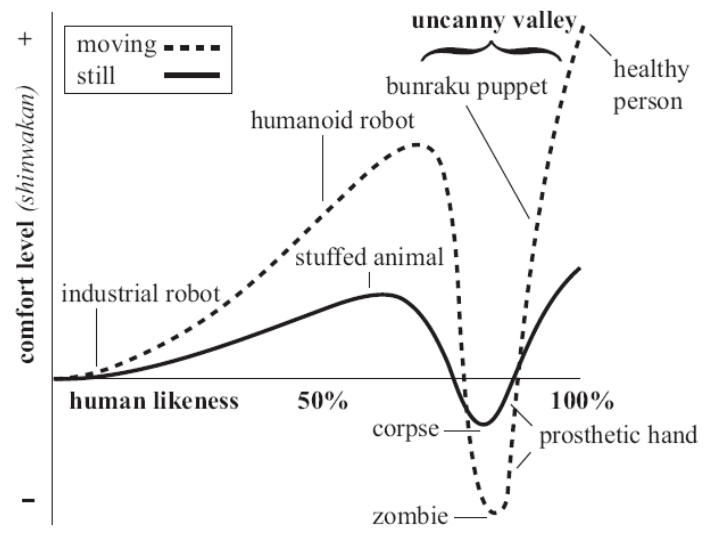

Fig. 3. The uncanny valley [24].

In detail, the Uncanny Valley phenomenon explains the relationship between the character's realistic level and the level of human's comfort and emotion. This phenomenon explains that characters designed in an unnatural approach can cause discomfort among people who see it. Based on the Uncanny Valley graph, the acceptance rate for a character increases positively when the character is human-likeness. However, the level of acceptance of humans is found to decrease to a negative level when the character is in a scary form. This is because humans rate such character designs as strange and eerie. This decline in acceptance rate is known as the Uncanny Valley. The human acceptance is back in the positive direction when the character is actual human. Although this phenomenon was initially directed towards the robotics field, the same phenomenon also occurred due to the realistic level of animated characters. Uncanny Valley's phenomenology for animation suggests that overly realistic animated characters resembling actual humans have the similar effect of discomfort and awe on the audience.

\section{The CONCEPTUAL Framework OF THE StUdy}

Based on the critical review of the current literature and the selected theories, the researchers proposed a conceptual framework of the talking-head animation as a pedagogical agent as shown in Fig. 4. As highlighted, a talking-head animation based on a character with a proper level of realism is expected to wield a significant effect on students' emotions in learning. Particularly, based on the theory of Control-Value of Achievement Emotions [31], positive emotions felt by students, such as the feeling of happiness or fun (enjoyment), during learning can help elevate heighten their motivation and emotions in learning. Certainly, positive emotions can help motivate students to keep learning over a meaningful duration. Nonetheless, the level of realism of the character of the talking-head may be the key factor that causes a change in students' emotions in the learning session. As such, it is important to identify the appropriate level of realism of such animation prior to developing and implementing it in the classroom.

As stressed earlier, a digital character looking too realistic could cause a negative effect on the state of motivation and emotions of users. Inevitably, the occurrence of such an event is due to mistakes in determining the proper design of the talking-head character. From the standpoint of the Uncanny Valley phenomenon, it thus becomes vividly clear that the level of realism of such a character is an extremely important element that needs to be highly emphasized in designing the talking-head animation to ensure users' emotion will not be compromised. Moreover, the negative emotions felt by students toward such a character can probably lower their level of motivation to the point that they become reluctant to continue with their learning. Unmitigated, such a state of affairs can have a lasting effect on their emotions in learning

In addition, the facial expressions of the character need to be given a strong emphasis in the design phase of the talking-head as instructional materials. Such an emphasis has its own merits given that, usually, users will judge a character with positive expressions, such as a smiling face, to be friendly. Consequently, exerting a positive effect on their emotions.

Collectively, all the above arguments or assertions suggest the imperative of identifying ideal talking-head with positive facial expressions design. Which, can significantly influence students' emotion and motivation of overall learning processes.

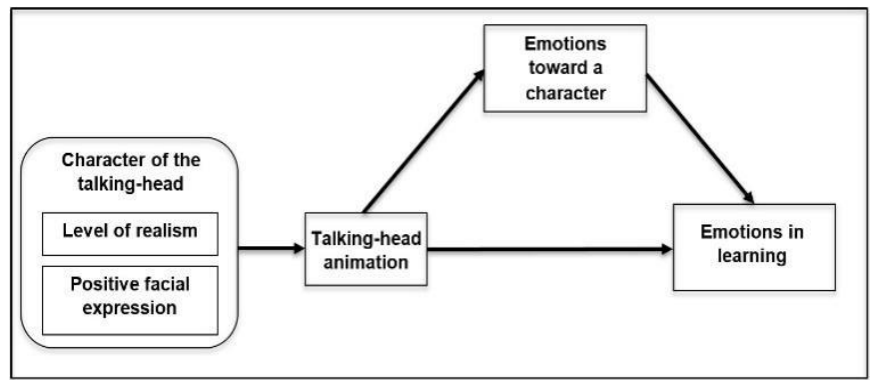

Fig. 4. The conceptual framework of the study.

\section{CONCLUSION}

Clearly, the talking-head animation has a huge potential that can be developed into a dynamic learning aid or tool. In fact, the use of such a learning tool can help the teaching practitioners (notably, teachers or lecturers) to diversify their teaching methods in the classroom.

The application of talking-head animations as a pedagogical agent in an interactive learning environment has 
a positive effect on students' emotions and motivations and is able to create meaningful learning experiences. Talking-head animations also have potential in promoting fun learning, interesting and attractive learning environment that will engage students in learning activities for longer duration. Talking-head animations designed with attributes such as cheerful and energetic are seen to have positive potential in enhancing students' motivation towards learning.

It is worth to note, however, that the commission of errors in the development of animations, especially in selecting the character with an appropriate level of realism and facial expression, can have a negative effect on students' emotions in their learning. In view of such a risk, studies need to be carried out to examine the effects of the use of the talking-head character with several levels of realism and positive facial expression on students' emotions. Specifically, the studies focused on the effects of students' emotions toward such a character and, subsequently, on whether the emotional effects on the level of realism could significantly influence students' emotions in learning. Clearly, the findings of such researches can provide guidelines in determining appropriate character that is able to promote positive learning.

\section{CONFLICT OF INTEREST}

The authors declare no conflict of interest.

\section{AUTHOR CONTRIBUTIONS}

Muhammad Ihsan Rokeman conducted the research; Ahmad Zamzuri Mohamad Ali is a grant leader and research supervisor; Mohd Khairulnizam Ramlie contributed for the knowledge; all authors had approved the final version.

\section{REFERENCES}

[1] C. K. Y. Chan, "Use of animation in engaging teachers and students in assessment in Hong Kong higher education," Innovations in Education and Teaching International, vol. 52, no. 5, pp. 474-484, 2015.

[2] J. C. Tu and Y. H. Chiang, "The influence of design strategy of peer learning on 3-D software learning," Eurasia Journal of Mathematics, Science \& Technology Education, vol. 12, no. 5, pp. 1263-1271, 2016.

[3] L. Xie, N. Sun, and B. Fan, "A statistical parametric approach to video-realistic text-driven talking avatar," Multimed. Tools Appl., vol. 73, no. 1, pp. 377-396, 2014.

[4] A. Z. M. Ali and M. N. Hamdan, "The effects of talking-head with various realism levels on students' emotions in learning," J. Educ. Comput. Res., vol. 55, no. 3, pp. 429-443, Oct. 2016.

[5] Y. Shiban et al., "The appearance effect: Influences of virtual agent features on performance and motivation," Comput. Human Behav., vol. 49 , pp. 5-11, 2015.

[6] N. L. Schroeder and C. M. Gotch, "Persisting issues in pedagogical agent research,” J. Educ. Comput. Res., vol. 53, no. 2, pp. 183-204, 2015.

[7] Y. Kim, J. Thayne, and Q. Wei, "An embodied agent helps anxious students in mathematics learning," Educ. Technol. Res. Dev., vol. 65 no. 1, pp. 219-235, 2017.

[8] N. L. Schroeder, "The influence of a pedagogical agent on learners' cognitive load," Educ. Technol. Soc., vol. 20, no. 4, pp. 138-147, 2017.

[9] R. K. Atkinson, "Optimizing learning from examples using animated pedagogical agents," J. Educ. Psychol., vol. 94, no. 2, pp. 416-427, 2002.

[10] H. I. Yung and F. Paas, "Effects of cueing by a pedagogical agent in an instructional animation: A cognitive load approach," Educ. Technol. Soc., vol. 18, no. 3, pp. 153-160, 2015.

[11] W. L. Tze, M. Z. Nor Azan, and S. Noraidah, "Exploring the affective, motivational and cognitive effects of pedagogical agent enthusiasm in a multimedia learning environment," Human-Centric Comput. Inf. Sci., vol. 7, no. 9, pp. 1-21, 2017.
[12] N. L. Schroeder, O. O. Adesope, and R. B. Gilbert, "How effective are pedagogical agents for learning? A meta-analytic review," J. Educ. Comput. Res., vol. 49, no. 1, pp. 1-39, 2013.

[13] F. Unal-Colak and O. Ozan, "The effects of animated agents on students' achievement and attitudes," Turkish Online J. Distance Educ., vol. 13, no. 2, pp. 96-111, 2012.

[14] L. Wang and F. K. Soong, "HMM trajectory-guided sample selection for photo-realistic talking head," Multimed. Tools Appl., vol. 74, no. 22, pp. 9849-9869, 2015.

[15] W. L. Johnson and J. C. Lester, "Face-to-face interaction with pedagogical agents, twenty years later," Int. J. Artif. Intell. Educ., vol. 26, no. 1, pp. 25-36, 2016.

[16] S. Saidatul Maizura et al., "The pedagogical agent in online learning: Effects of the degree of realism on achievement in terms of gender," Contemp. Educ. Technol., vol. 1, no. 2, pp. 175-185, 2010.

[17] S. Domagk, "Do pedagogical agents facilitate learner motivation and learning outcomes?" J. Media Psychol., vol. 22, no. 2, pp. 82-95, 2010.

[18] X. Peng, H. Chen, L. Wang, and H. Wang, "Evaluating a 3-D virtual talking head on pronunciation learning," Int. J. Hum. Comput. Stud., vol. 109, no. May 2017, pp. 26-40, 2018.

[19] K. F. MacDorman, R. D. Green, C. C. Ho, and C. T. Koch, "Too real for comfort? Uncanny responses to computer generated faces," Comput. Human Behav., vol. 25, no. 3, pp. 695-710, 2009.

[20] E. Um, J. L. Plass, E. O. Hayward, and B. D. Homer, "Emotional design in multimedia learning," J. Educ. Psychol., vol. 104, no. 2, pp. 485-498, 2012.

[21] F. T. Villavicencio and A. B. I. Bernardo, "Positive academic emotions moderate the relationship between self-regulation and academic achievement," Br. J. Educ. Psychol., vol. 83, no. 2, pp. 329-340, 2013.

[22] A. Tinwell and R. J. S. Sloan, "Children's perception of uncanny human-like virtual characters," Comput. Human Behav., vol. 36, pp. 286-296, 2014.

[23] K. F. MacDorman and D. Chattopadhyay, "Reducing consistency in human realism increases the uncanny valley effect; increasing category uncertainty does not," Cognition, vol. 146, pp. 190-205, 2016.

[24] M. Mori, "The uncanny valley (K. F. MacDorman \& N. Kageki, Trans.)," IEEE Robot. Autom. Mag., vol. 19, no. 2, pp. 98-100, 2012.

[25] H. Lei and Y. Cui, "Effects of academic emotions on achievement among mainland Chinese students: A meta-analysis," Soc. Behav. Pers., vol. 44, no. 9, pp. 1541-1554, 2016.

[26] C. Mega, L. Ronconi, and R. De Beni, "What makes a good student? How emotions, self-regulated learning, and motivation contribute to academic achievement," J. Educ. Psychol., vol. 106, no. 1, pp. 121-131, 2014.

[27] M. N. Hamdan, "Tahap realistik karakter animasi talking-head dan kesannya terhadap emosi dan prestasi pembelajaran," Unpublished doctoral thesis, Universiti Pendidikan Sultan Idris, Tanjong Malim, Perak, Malaysia, 2015

[28] R. Pekrun, "The control-value theory of achievement emotions: Assumptions, corollaries, and implications for educational research and practice," Educ. Psychol. Rev., vol. 18, no. 4, pp. 315-341, 2006.

[29] K. Muñoz, J. Noguez, L. Neri, P. M. Kevitt, and T. Lunney, “A computational model of learners' achievement emotions using control-value theory," Educ. Technol. Soc., vol. 19, no. 2, pp. 42-56, 2016.

[30] A. R. Artino, E. S. Holmboe, and S. J. Durning, "Control-value theory: Using achievement emotions to improve understanding of motivation, learning, and performance in medical education: AMEE guide No. 64," Med. Teach., vol. 34, no. 3, pp. e148-e160, 2012.

[31] R. Pekrun, A. C. Frenzel, T. Goetz, and R. P. Perry, "The control-value theory of achievement emotions," in Emotion in Education, P. A Schutz and R. Pekrun, Eds. Amsterdam: Elsevier, 2007, pp. 13-36.

[32] R. Pekrun, T. Goetz, W. Titz, and R. P. Perry, "Academic emotions in students' self-regulated learning and achievement: A program of qualitative and quantitative research," Educ. Psychol., vol. 37, no. 2, pp. 91-105, 2002.

[33] R. Pekrun and L. Linnenbrink-Garcia, "Academic emotions and student engagement," in Handbook of Research on Student Engagement, vol. 7, no. 2, S. L. Christenson, A. L. Reschly, and C. Wylie, Eds. New York: Springer New York, 2012, pp. 259-282.

[34] R. Pekrun, T. Goetz, W. Titz, and R. P. Perry, "Academic emotions in students' self-regulated learning and achievement: A program of qualitative and quantitative research," Educ. Psychol., vol. 37, no. 2, pp. 91-106, 2002.

[35] S. Lay, N. Brace, G. Pike, and F. Pollick, "Circling around the uncanny valley: Design principles for research into the relation between human likeness and eeriness," Iperception, vol. 7, no. 6, pp. 1-11, 2016. 
[36] F. Kaba, "Hyper-realistic characters and the existence of the uncanny valley in animation films," Int. Rev. Soc. Sci. Humanit., vol. 4, no. 2, pp. 188-195, 2013.

[37] S. Kunz, "The problem of realism in animated characters - Has the uncanny valley been crossed?" in Proc. International Conference on Illustration \& Animation, 2015, pp. 74-86.

Copyright $\odot 2020$ by the authors. This is an open access article distributed under the Creative Commons Attribution License which permits unrestricted use, distribution, and reproduction in any medium, provided the original work is properly cited ( $\underline{\text { C BY 4.0) }}$.

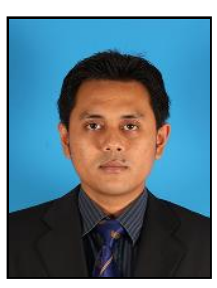

Muhammad Ihsan Rokeman is a $\mathrm{PhD}$ student in multimedia design, Faculty of Art and Creative Industry, Universiti Pendidikan Sultan Idris, Perak, Malaysia. Currently, he is a full-time lecturer in the Department of Mathematics, Science and Computers at Politeknik Sultan Azlan Shah, Perak, Malaysia. He obtained a bachelor degree (hons) of information technology (multimedia studies) from Universiti Kebangsaan Malaysia in 2005 and a master degree of multimedia education from Universiti Pendidikan Sultan Idris in 2015.

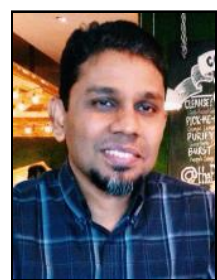

Ahmad Zamzuri Mohamad Ali is a professor of multimedia in the Faculty of Art, Computing and Creative Industry, Universiti Pendidikan Sultan Idris, Malaysia. He has a PhD in instructional multimedia from Universiti Sains Malaysia, master in education and bachelor degree in electrical engineering from Universiti Teknologi Malaysia. Has taught both face-to-face and online classes in higher education for over 20 years. His research and publication interest is instructional technology, specifically in multimedia design, programming teaching and learning and hardware software interfacing. In his 10 years' experience as an academic in UPSI, he has published 4 books, which one obtained National Book Award 2018 and over 100 articles in journals, chapter in books, national and international proceedings, and monthly periodical.

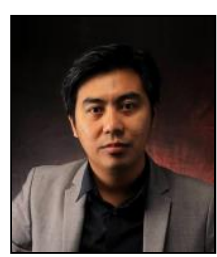

Mohd Khairulnizam Ramlie is studying for the doctor of philosophy in multimedia design, Faculty Of Art, Computing and Creative Industry, Sultan Idris Education University, Perak, Malaysia. He is currently a full-time lecturer at the Department of Graphic Design and Digital Media, Faculty of Art and Design, Universiti Teknologi MARA (Perak), Malaysia. He obtained the bachelor's degree (hons) in graphic design and digital media in 2008 and received the master's degree in visual communication and new media in 2012, both from Faculty of Art and Design, Universiti Teknologi MARA, Malaysia. 